\title{
Three-dimensional numerical study on aerodynamics of non-flapping bird flight
}

\author{
AMIT SONI and SHALIGRAM TIWARI* \\ Department of Mechanical Engineering, Indian Institute of Technology Madras, Chennai 600036, India \\ e-mail: shaligt@iitm.ac.in
}

MS received 10 June 2017; revised 23 September 2018; accepted 9 October 2018; published online 22 January 2019

\begin{abstract}
Numerical investigations have been carried out to study aerodynamics of non-flapping characteristics of bird flight. Commercial software ANSYS Fluent 16.1 has been used for three-dimensional computations by considering four types of wing models. At first, square prisms with built-in side flaps are considered and the effects of Reynolds number (Re), angle of attack and dihedral angle on flow characteristics have been investigated. Thereafter, flow past actual bird wing has been considered for wings of owl, seagull, teal and bat. Role of shear layer formation at mid-span of wings has been illustrated with the help of streamline plots for different values of Re. In addition, pulsating flow is imposed on inlet velocity and the responses are obtained in form of force coefficients, phase portraits, time-dependent signals and their spectra.
\end{abstract}

Keywords. Natural flyers; non-flapping bird wing; length ratio; unsteady simulation of bird flight; lift; drag.

\section{Introduction}

Bird flight can be studied under four categories, viz., considering it as a fixed wing problem similar to an aircraft, flapping wing model without any flexibility in the wing, non-flapping model with flexible wing and flapping model with flexible wing. Bird wing structure can also be a major concern in determining the mechanical properties of wing under the influence of aerodynamic forces. As a result of evolution and natural selection, bird flight plays a significant role in understanding flow behaviour observed in nature. In nature, different types of wing designs exist, viz. elliptical wing, high lift wing and high aspect ratio wing. Elliptical wings are useful for forested habitat and have slots to prevent stall at low speed. Vultures, eagles and other birds of prey carry heavy loads and their wings produce high lift at low speed. High aspect ratio wings are applicable for long flights and reduce turbulence due to swept back wings. The structure of bird wing has been focus of limited studies in the past because of its mechanical property that plays a vital role in deciding aerodynamic performance [1]. Bird wing is adaptive in nature which has its own benefits in terms of manoeuvrability, efficiency and control over wing motion [2]. The study of flow past bird in flight is complex and challenging due to scaling problem encountered in both experimental as well as in computational study [3].

Surface textures of wing for birds have been studied and attempt is made to understand the boundary layer

*For correspondence separation using surface riblets [4]. Wings of natural flyers can hold rolls of shear layer that remain attached and locked to wings having hairy structure while for wings without such structure the separation region is wider [5]. Wing consists of different types of feathers that play important role during flight. The feathers are prone to aerodynamic forces and act as reversible airfoil during take-off [6]. Mechanoreceptors associated with feathers act as flow sensors. Based on vibration of feathers and flow detachment from wing surface, flow stall point is predicted by [7]. In addition, mounting of wing tip devices reduces drag due to partial recovery of tip vortex energy. It has been reported by [8] that even though wing tip reduces induced drag similar to winglets, the parasitic drag may get increased due to increased surface area.

Wings are equipped with feathers that cause drag reduction and vibrate with frequency dependent on value of Reynolds number (Re). It has been confirmed by experiments that drag reduction of $22 \%$ could be achieved by mounting a flexible flap behind a bluff body [9]. In the past, various experiments have been conducted on bird wing and drag coefficient is found to lie in the range 0.03-0.13 [10]. Boundary layer separation for different wing designs have been reported [11]. The performance of bird wing is normally quantified in terms of reduced drag and delayed stall which has been found to be relatively weaker as compared to standard airfoil. However, the bird wing shows better performance at higher angles of attack [12] by delaying the stall. Experiments conducted on wings of Barn owl and pigeon have reported that thicker wing of owl helps it to fly at low speed whereas pigeon has to flap wings faster that 
makes its wing noisier as compared to that of an owl. Owls fly almost silently as compared to other birds [13, 14].

Flow parameters also affect the flying behaviour of birds. One of the most influencing factors during flight is the nature of incoming flow. Drag reduction is observed in case of Zebra Finch when velocity increases from 6 to $10 \mathrm{~m} / \mathrm{s}$ [15]. Moreover, angle of attack and dihedral angle also change the flight conditions. Flight becomes unstable when increase in dihedral angle is caused by yawing and rolling motions [16]. Birds flap wings in downward and upward direction with amplitude being controlled based on necessity. During downward and upward strokes, various phase shifts occur and passive controllers help flows to stabilize at different phases of flapping [17]. Unfolding of the wing is passively controlled which is dominated by centrifugal rather than aerodynamic and gravitational forces during flapping motion [18]. Different types of flying patterns for birds have been suggested based on the size and shape of the wing. There exist basically two types of flight, viz. hovering and intermittent flight. In fact, Hummingbird is the only vertebrate that can perform hovering motion whereas in small birds the style of flight is of intermittent type. The intermittent flights are further divided into two groups, viz. flap-bounding and flap-gliding flights. Birds can change their flying style from flap-bounding to flapgliding based on flight conditions [19] and path of wing motion may be different for different birds [20]. It has been reported [21] that bat wing has much complex motion as compared to bird wing due to unique ability of bat in slow flying and manoeuvring. Bats are capable of morphing their wings thereby acquire fully controlled motion because of the joint structure present in the wing. However, birds are equipped with feathers due to which limited control can be achieved on their motion.

In the present study, flow simulations have been performed for various types of models. Initially, flows past square prism having built-in side flaps are considered. Effect of geometrical and flow parameters are studied to cover overall panorama of bird flight with the help of simple geometry. The flow Reynolds number (Re), length ratio (LR) and dihedral angle $(\lambda)$ are the main variable parameters in the present study. These bring out the importance of incoming flow, length of flappers and upward dihedral angle. At later stage, the present study explains the flow behaviour for naturally inspired wing profiles. Wing profiles of different birds are considered and modelled with the help of ANSYS ICEM 16.1. Selection of Re has been made such that it would cover the approximate range of Re observed for natural flyers. To account for the effect of gusty atmosphere, the incoming flow is imparted a forcing frequency with the help of User Defined Function (UDF). Results are presented in the form of streamlines, drag and lift, contours and phase portrait.

The objective of the present research is to study the physical problem existing in nature with the help of simpler geometries such as a square prism having built-in side flaps which mimics the size and position of wings for different birds and fixed-wing aircraft. Investigations in the present study are expected to help in understanding the flow behavior of selected 3-D wings by considering the parameters such as Re, angle of attack and gusty flow.

\section{Present study}

The present work is categorized into two sections, i.e., square prism having built-in side flaps and a study of flow past 3-D wings. To elucidate 3-D flow behaviour, initial studies are carried out for flow past square prism. In this case, effect of both flow and geometrical parameters has been studied on flow and dynamic characteristics. Subsequently, actual bird wings have been chosen to investigate the effect of Re, angle of attack and gusty atmosphere for flow over non-flapping wings. The computational domain for owl wing has been shown in figure 1. Length of domain is kept as $L_{3}=20 c_{m}$, height of domain is $L_{1}=10 c_{m}$ and
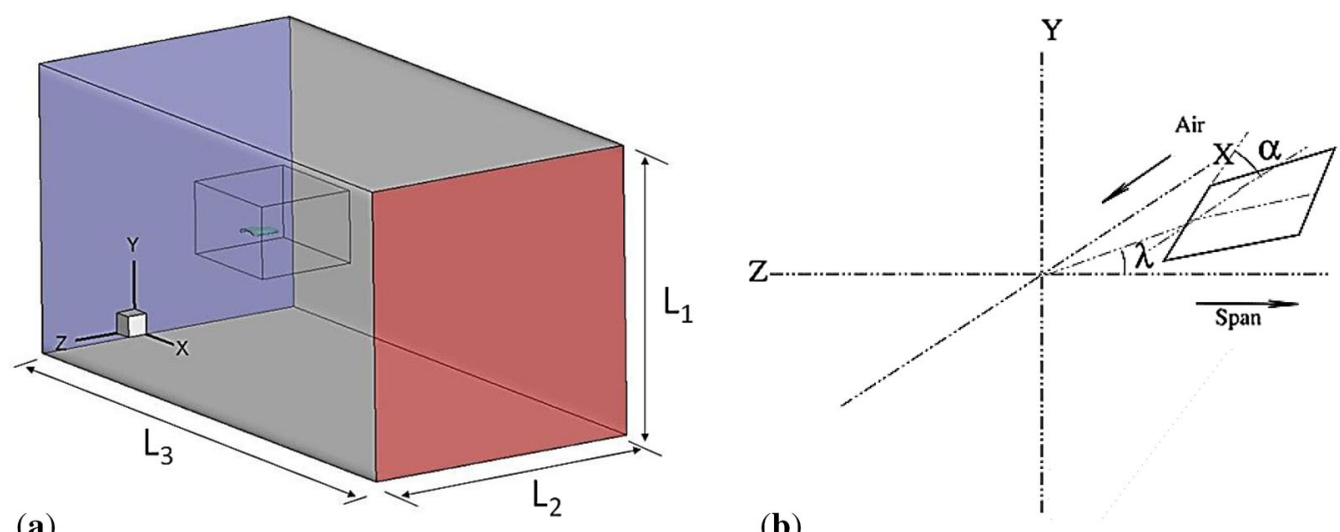

(b)

Figure 1. (a) Computational domain of wing used for numerical simulation, (b) illustration of angle of attack $(\alpha)$ and dihedral angle $(\lambda)$. 
width of domain is $\mathrm{L}_{2}=10 \mathrm{c}_{\mathrm{m}}$. same computational domain has been used even for computing flow past other wings. Three-dimensional numerical computations have been carried out for different values of Re, angle of attack, dihedral angle and wing shapes. Dimensions of wings are chosen as reported in [22] and figure 2 shows the scaled model of different wing designs in meters used for simulation. Here Re is defined on the basis of mean chord length $\left(\mathrm{c}_{\mathrm{m}}\right)$ as

$$
\operatorname{Re}=\frac{\rho U_{\infty} c_{\mathrm{m}}}{\mu}
$$

where $c_{m}$ is the mean chord length, defined as $c_{m}=A_{p} / L$, $A_{p}$ is projected area and $L$ is length of the wing.

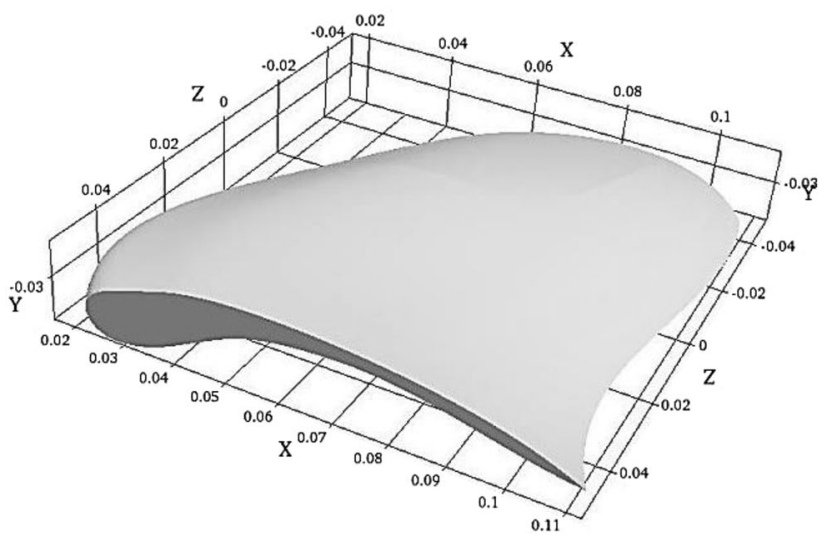

(a)

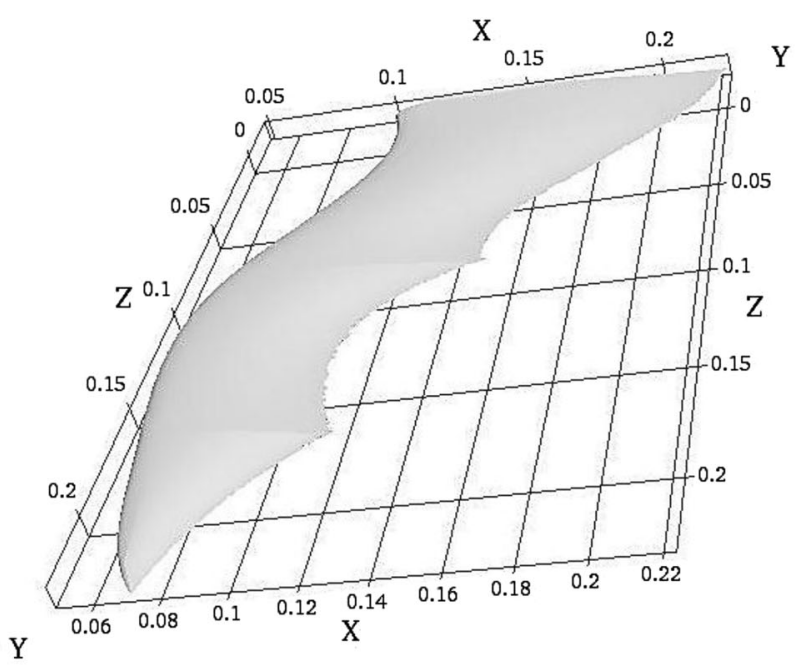

(c)

\section{Governing equations and boundary conditions}

\subsection{Governing equations}

For three-dimensional incompressible flow, the governing equations of continuity and momentum are given as

$$
\nabla \cdot \vec{V}=0
$$

$$
\frac{\partial \vec{V}}{\partial t}+\vec{V} \cdot \nabla \vec{V}=-\frac{1}{\rho} \nabla p+v \nabla^{2} \vec{V}
$$

where $\vec{V}$ represents velocity vector having its Cartesian components $u, v$ and $w$ along $x$-, $y$ - and $z$-directions, respectively. Here $p$ is a static pressure, $\rho$ is density and $v$ is the kinematic viscosity of the fluid.

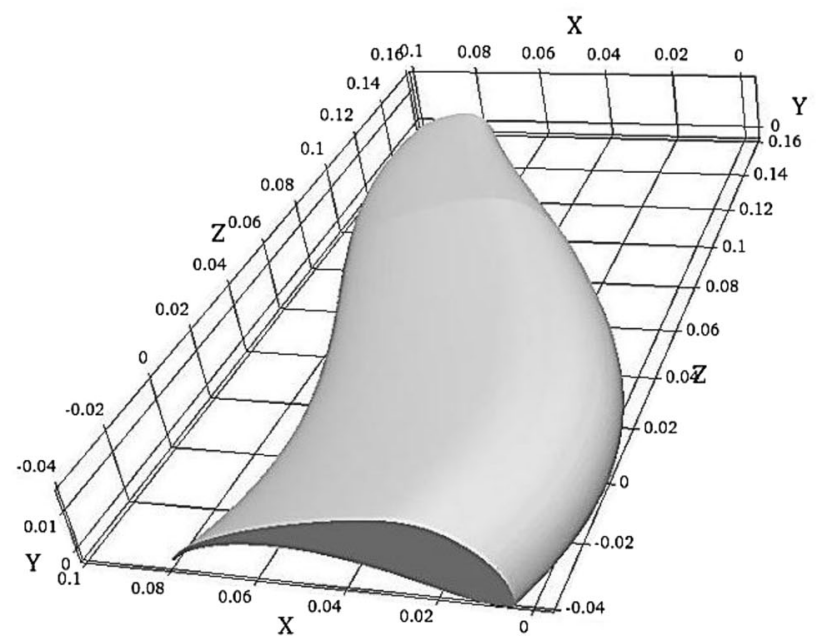

(b)

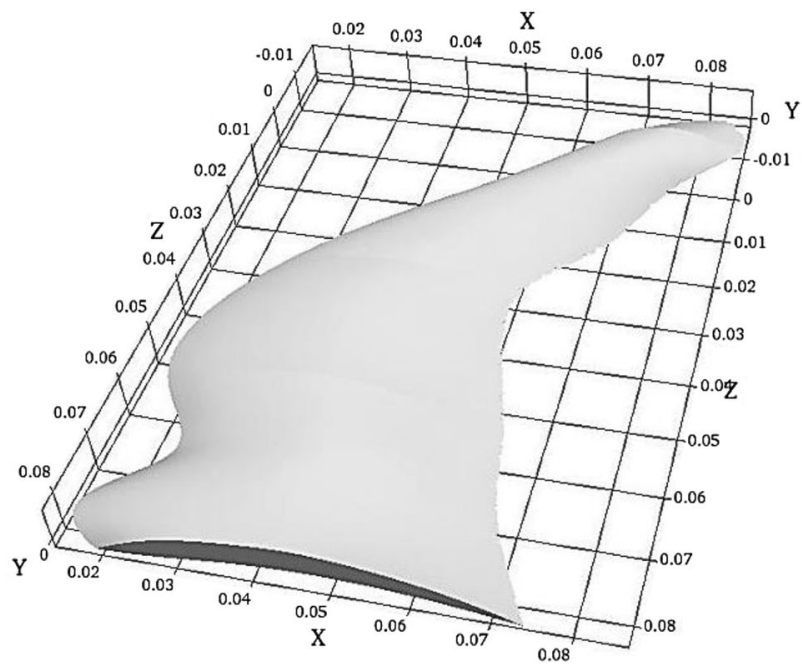

(d)

Figure 2. Scaled model of bird and bat used for simulation. 


\subsection{Boundary conditions}

Boundary conditions imposed at different faces of the computational domain are as follows.

- Inlet: Uniform velocity, i.e. $u=U_{\infty}, v=0$ and $w=0$

- Outlet: Outlet pressure $p=p_{\infty}$

- Side wall: Free-slip, i.e. $w=0, \frac{\partial u}{\partial z}=0$

- Top and bottom wall: Free-slip, i.e. $v=0$ and $\frac{\partial u}{\partial y}=0$

- Bird body and wing: No-slip, i.e. $u=0, v=0$ and $w=0$.

\section{Grid and numerical technique}

\subsection{The grid}

Structured grids have been used for simple geometry and hybrid grids are generated for complex geometry. An interface has been created to separate structured and unstructured zones for complex geometries. Computational grids are structured in case of square prism and standard geometrical shapes are considered for wing plan form like rectangular, elliptical and semi-elliptical whereas for scaled model resembled to actual wing of the bird, hybrid grids have been used. Prism layer has been made around owl wing to capture the flow characteristics in the boundary layer. Schematic of grid mesh for owl wing has been shown in figure 3. Grid independence study has been carried out by varying number of nodes along mean chord length and results are presented in table 1. Based on the grid independence study, grid having 100 nodes along chord direction has been chosen for computations in the present study at $\operatorname{Re}=2000$.

\subsection{Numerical technique}

The governing flow equations are solved by using finite volume based commercial software ANSYS Fluent 16.1.

(a)

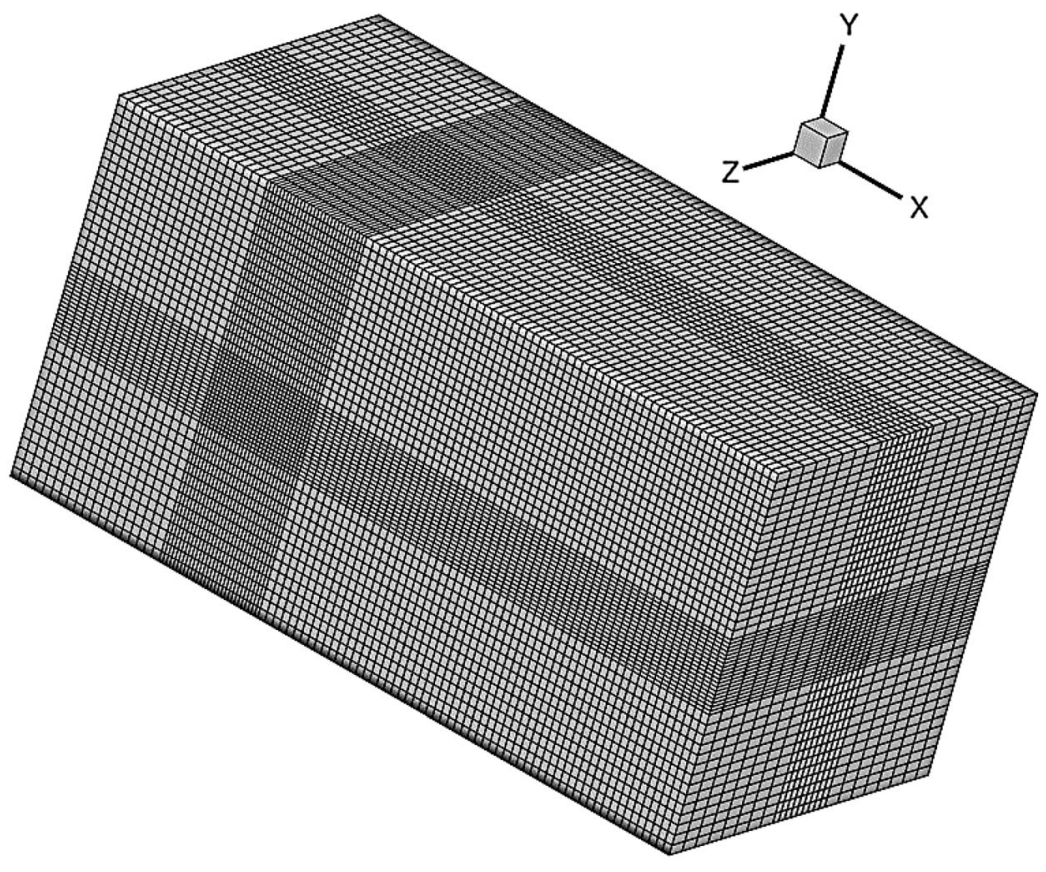

(b)
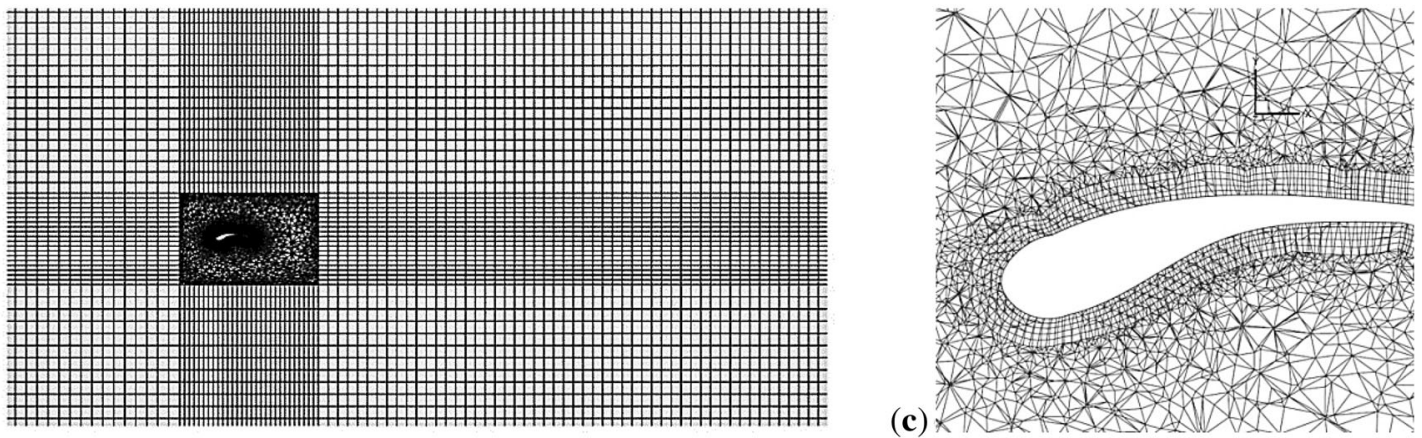

Figure 3. Grid used for computations of flow past an owl wing (a) volumetric grid, (b) grid layout in $\mathrm{x}-\mathrm{y}$ plane and (c) prism layer near wing surface. 
Table 1. Grid independence study for varying nodes on along mean chord length.

\begin{tabular}{lc}
\hline Number of grids along $\mathrm{c}_{\mathrm{m}}$ & Mean drag coefficient \\
\hline 50 & 0.1025 \\
75 & 0.1020 \\
100 & 0.1017 \\
125 & 0.1017 \\
\hline
\end{tabular}

The flow equations have been solved by an algorithm based on semi-implicit pressure linked equations (SIMPLE) for pressure-velocity coupling. For spatial discretization, least squares based technique has been used along with second order upwind to discretize the convective terms. First order implicit scheme has been used for temporal discretization. Due to geometric complexity of the model, unstructured grids are used in a region close to the model whereas structured grids are used in far field region to save memory allocation and computational time. Prism layers have been created to capture the gradients in the boundary layer. Selection of model for computation is based on wake formation. For low Re, i.e., $\mathrm{Re}=100$ to 1000 , laminar viscous model has been chosen and above $\mathrm{Re}=1000$ turbulence model (Spalart-Allmaras) has been used for numerical investigations [23, 24].

\section{Results and discussions}

\subsection{Validations of computations}

Numerical results from the present computations have been compared with those reported from experimental and numerical studies by [25]. Figure 4 presents variation of steady state drag and lift coefficients reported by [25] and obtained from the present computations. Experimental results obtained by [25] for a rectangular plate of aspect ratio 2 in a tow tank were used to validate results from their own numerical study at $\operatorname{Re}=100$. It can be seen that the results from present computations show close match, i.e., with maximum deviation of $7 \%$ at $\alpha=$ $60^{\circ}$ with experimental results of Taira et al [25]. Figure 4(c) shows comparison of lift coefficient variation for low Re airfoil such as owl and seagull wings, for different values of angle of attack against results reported by Kondo [26].
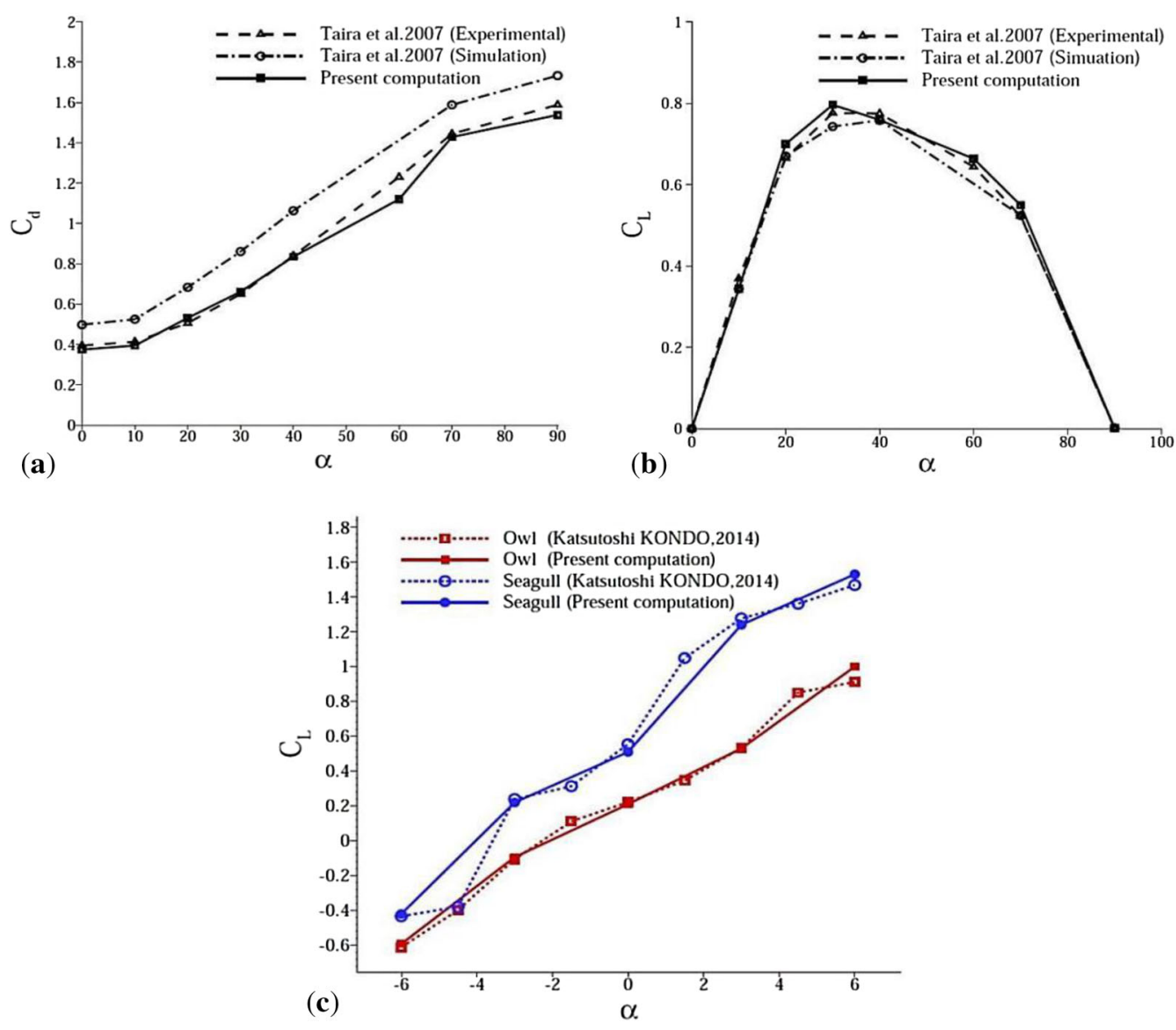

Figure 4. Comparison of steady state (a) drag, (b) lift at $\mathrm{Re}=100$ for different values of angle of attack and (c) lift coefficient at Re 23000 for different values of angle of attack for owl and seagull wing (2-D). 

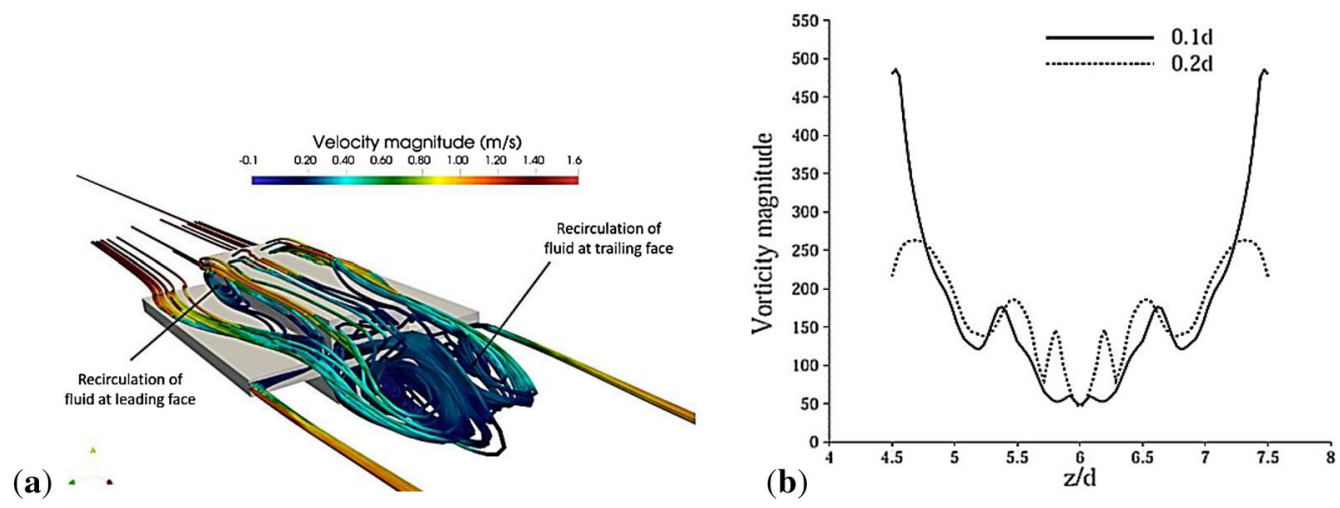

Figure 5. Wake structure for (a) $L R=1$ superimposed with velocity magnitude at $R e=1000$, (b) variation of vorticity magnitude for $\mathrm{LR}=1$ at different location from trailing face.

\subsection{Flow past square prism with built-in side flaps}

Initially computations are performed to investigate flow past square prism with built-in side flaps. For definition of $\mathrm{Re}$, side of square prism (d) is chosen as the characteristic dimension. Such a study aims to reveal effect of side flaps

(a)
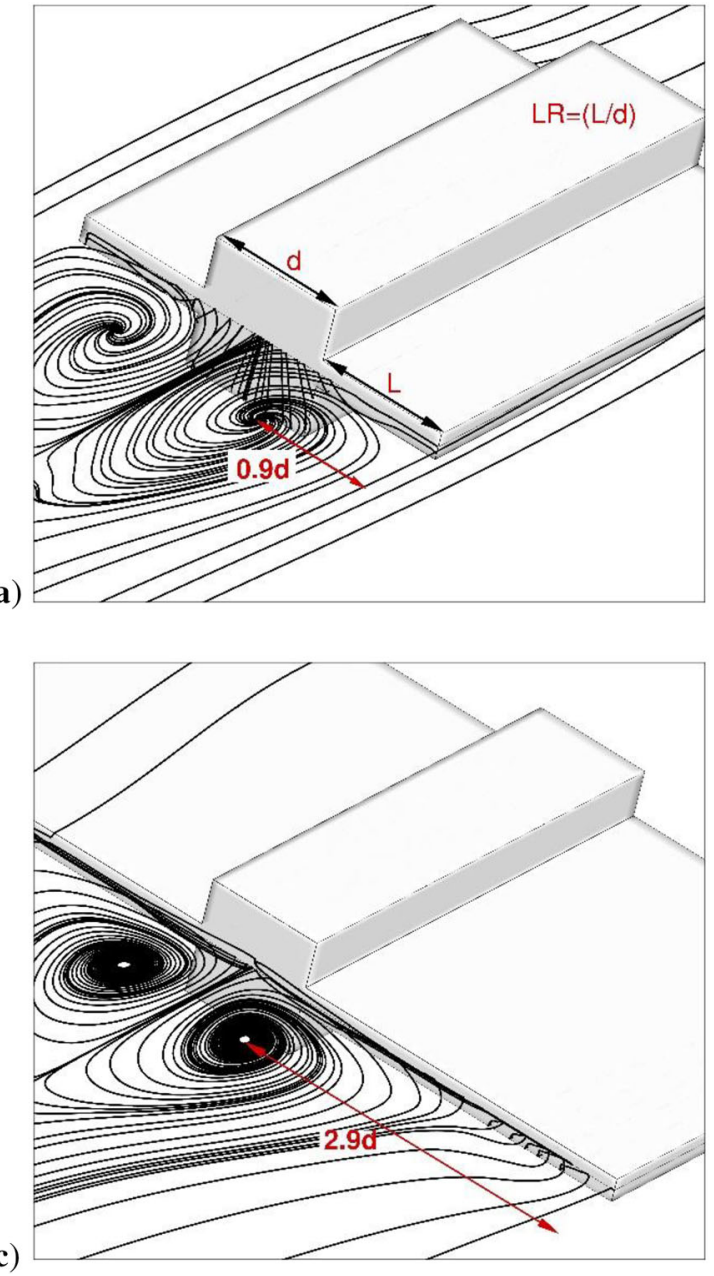

on flow behaviour to understand their role in modification of aerodynamic characteristics. Results from preliminary computations of author's own study [27] confirm that midplane position of flappers is associated with minimum drag thereby is best suited for gliding flight. That is why
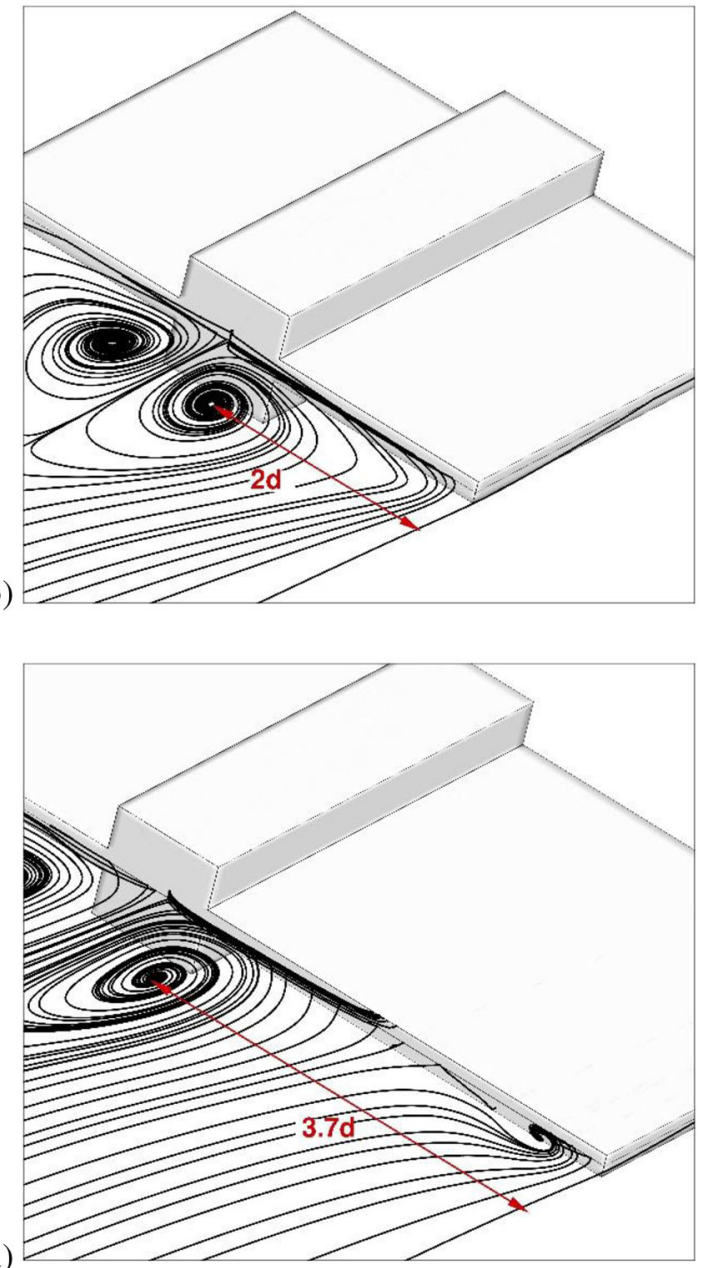

Figure 6. Time-averaged streamlines indicating the position of bubble center from wing-tip along the spanwise direction for (a) $L R=$ 1 , (b) $\mathrm{LR}=2$ and (c) $\mathrm{LR}=3$ and $\mathrm{LR}=4$, at $\mathrm{Re}=1000$. 


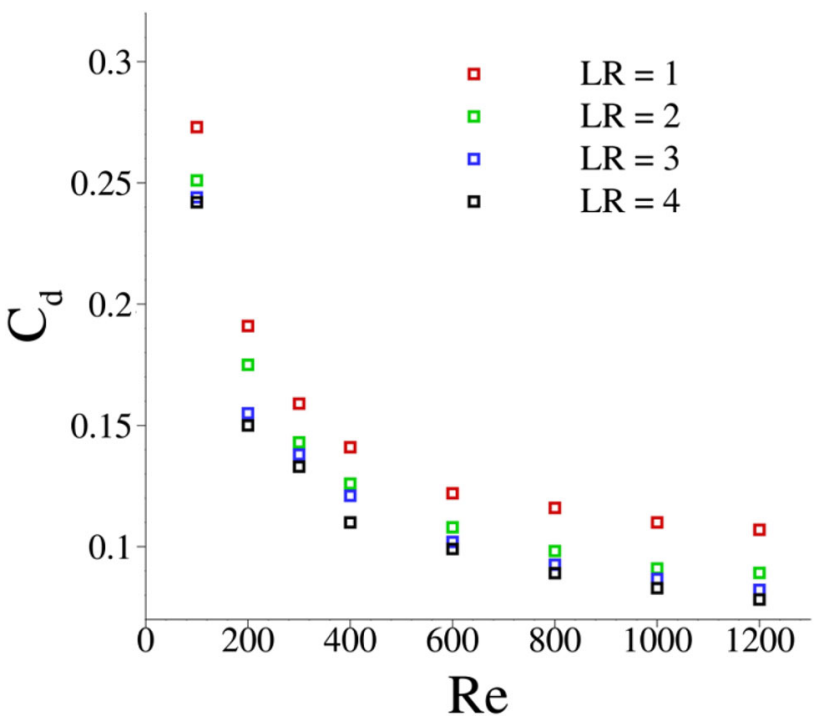

Figure 7. Variation of mean drag coefficient with change in Re for different values of LR.

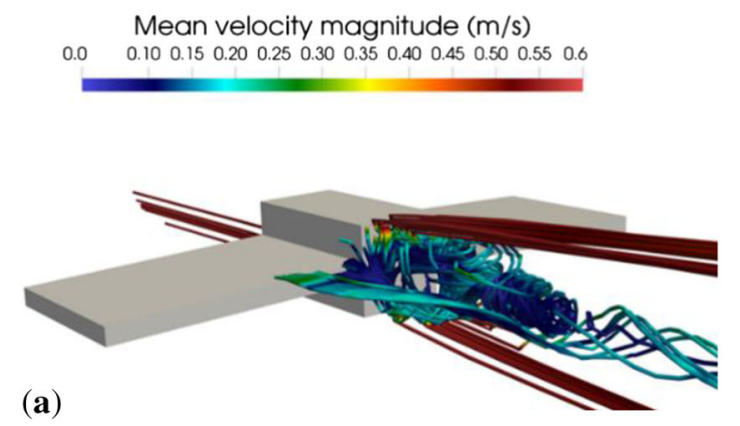

Figure 8. Representation of flow structure formed at $\operatorname{Re}=400$ for $(\mathbf{a}) \lambda=-2^{\circ}$ and (b) $\lambda=6^{\circ}$.
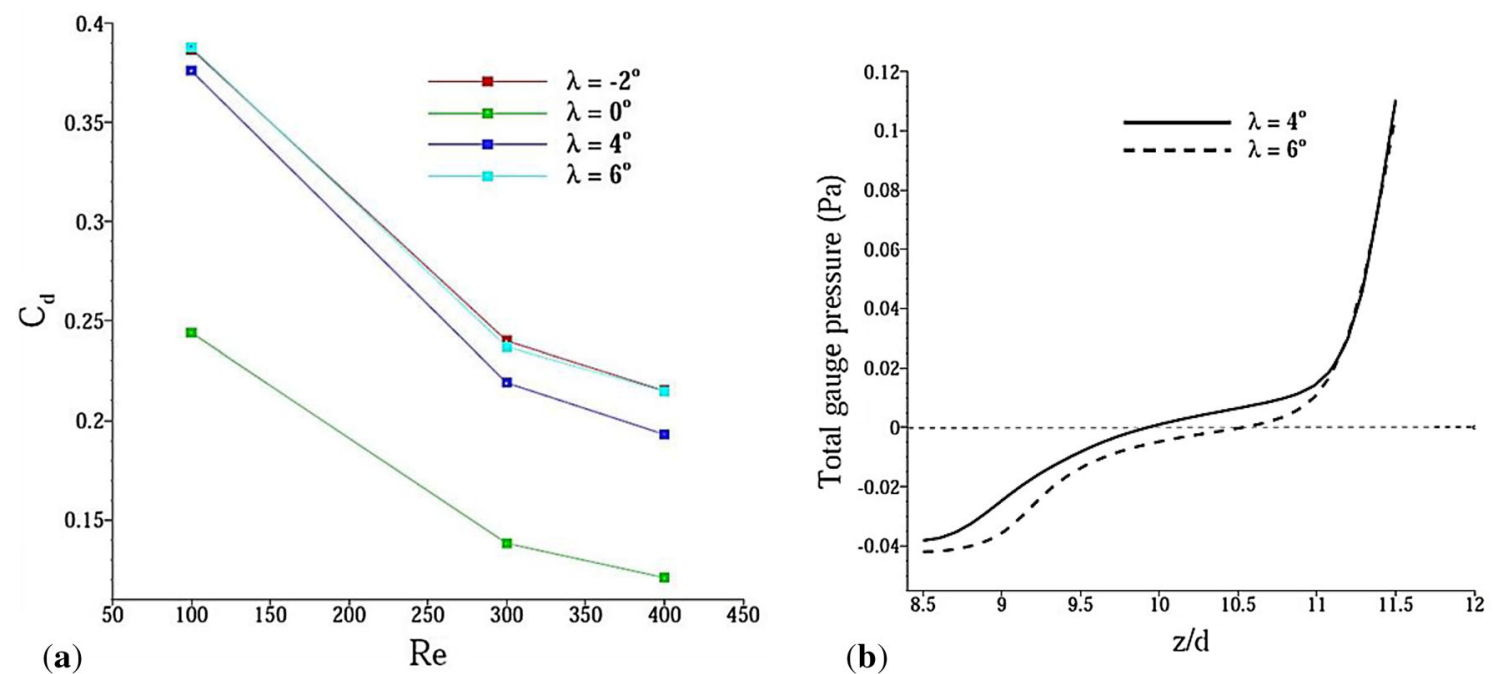

Figure 9. (a) Variation of drag coefficient for different values of dihedral angle for square prism having length ratio (LR $=3$ ), (b) variation of total gauge pressure for different values of dihedral angle at $\mathrm{Re}=400$. arrangement of wing for all the cases considered in the present study corresponds to mid-plane position.

5.2a Effect of Re and length ratio: Span length of wings varies from species to species. Wings may have structures that are broad and short, long and pointed or broad with slots on wing tip depending on forested zone. Pointed wings have smaller wing tip area, thereby reduce the induced drag. Such type of wing structure has an advantage at the time of take-off, climb, cruise and landing. Short wings have a high roll rate as compared to long wings due to smaller value of moment of inertia. Present simulations have been carried out to study the effect of length ratio (LR) and $\operatorname{Re}(100-1200)$ on the aerodynamic forces such as drag and lift. Length ratio (LR) is defined as the ratio of length of wing along spanwise direction to that of the side of square $\left(L / D_{\text {ref }}\right)$ where $D_{\text {ref }}$ is the side of square prism. Due to symmetry of the body, lift coefficient is close to zero for all the cases of square prism having mid-plane arrangement [25]. Figure 5 shows time-averaged streamtraces/streamsurfaces at $\mathrm{Re}=1000$ superimposed with

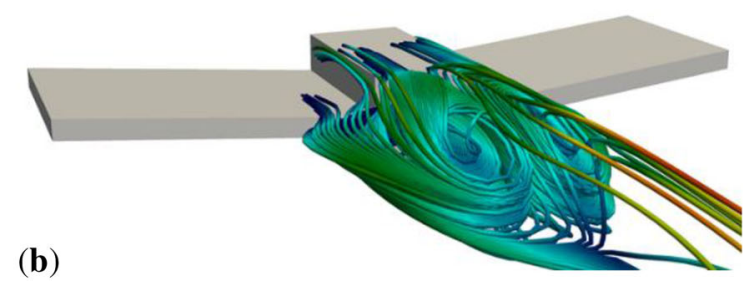

\section{(b)}

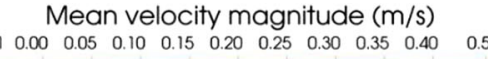


(a)

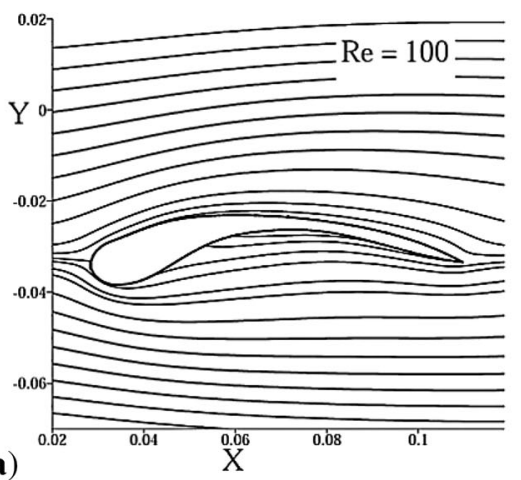

(d)

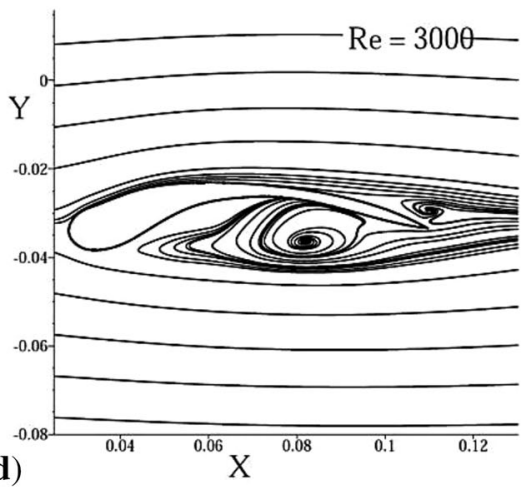

(b)

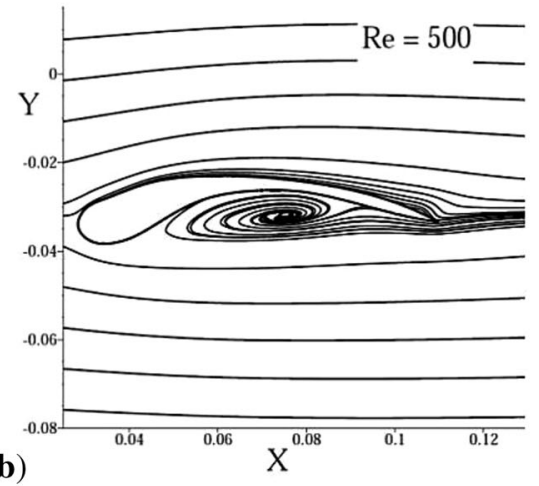

(c)
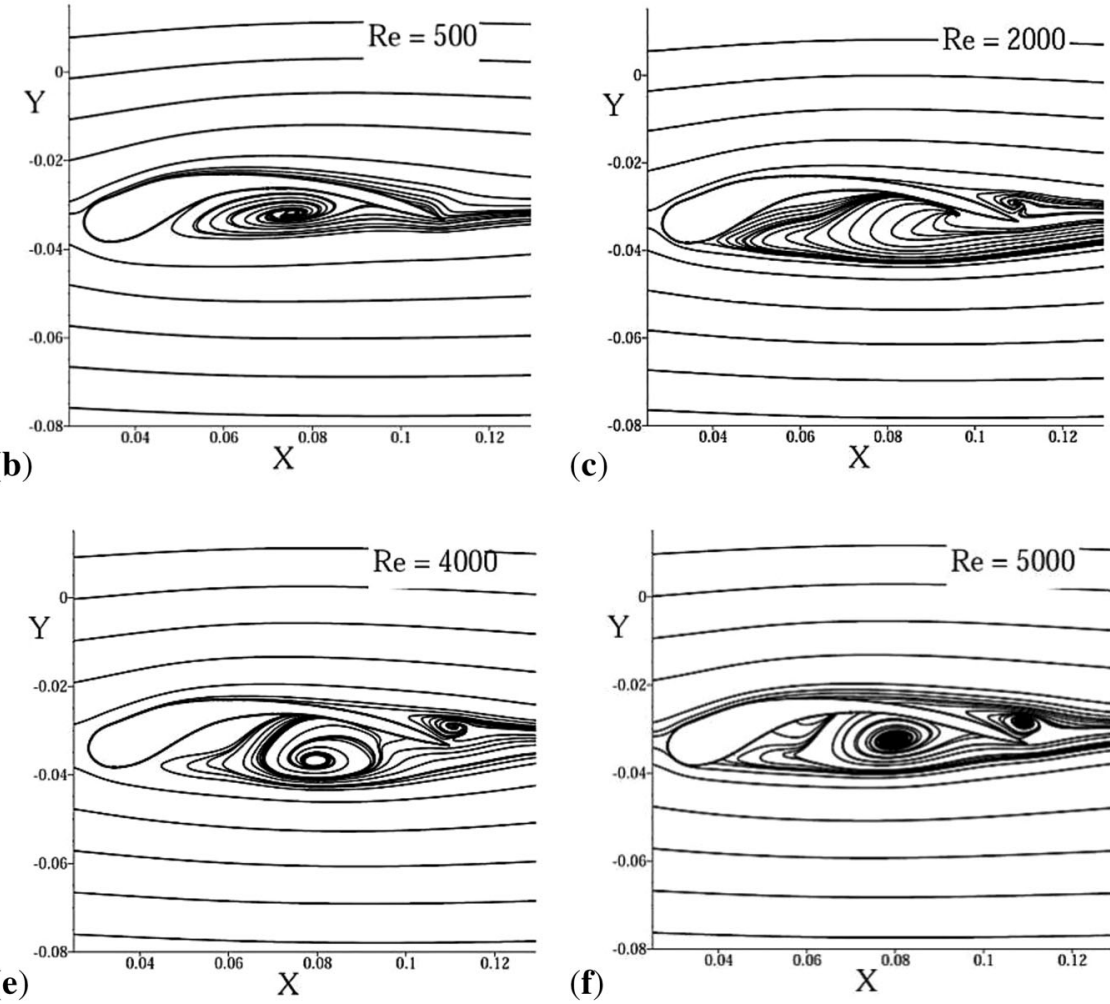

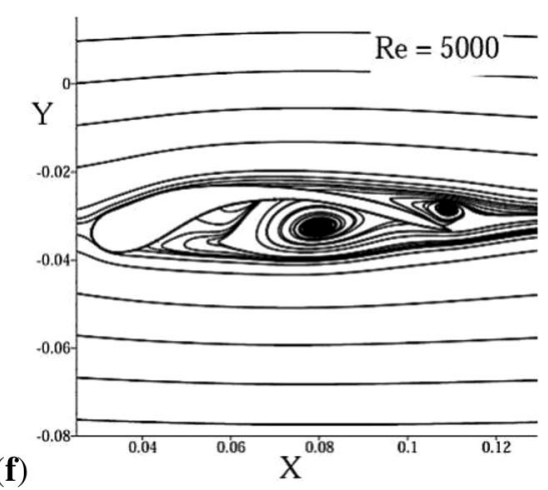

(f)

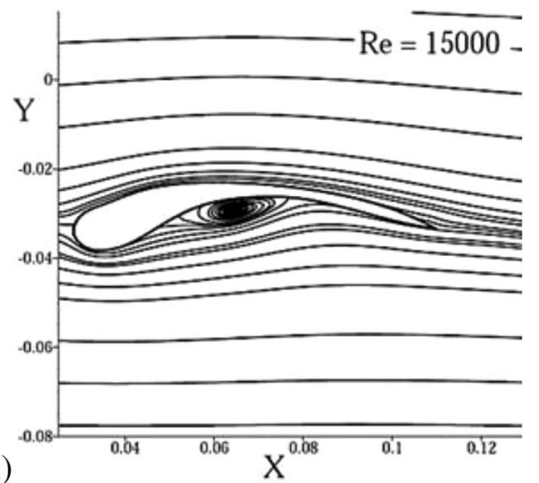

(h) (g)

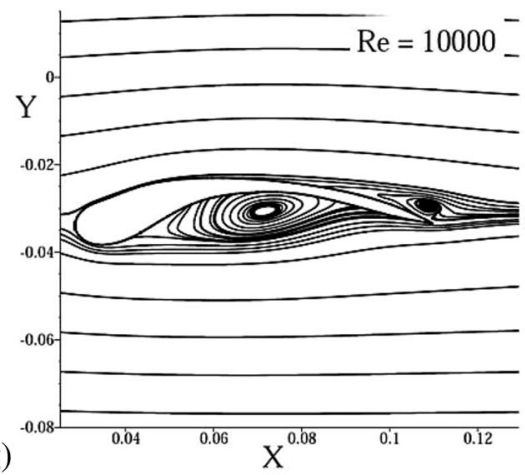

Figure 10. Formation of bubble over owl wing at mid-span wing for Re values of (a) 100, (b) 500, (c) 2000, (d) 3000, (e) 4000, (f) 5000, (g) 10000 and (h) 15000 .

velocity magnitude. For $L R=1$, it is seen that recirculation occurs at leading and trailing faces of the body as shown in figure 5(a). Figure 5(b) shows the variation of vorticity magnitude along spanwise direction, a sudden increase in magnitude between $\mathrm{z} / \mathrm{d}=5$ to 5.5 being observed due to interaction between the wing and body.

Figure 6 presents time-averaged streamlines at mid-plane and the distance of bubble centre from wing tip for different values of $L R$ at $R e=1000$. It has been seen that more or less centre of bubble forms at the junction of wing for all the values of LR. In addition, size of the circulation zone reduces with increase in value LR as illustrated in figure 6(a)-(d). In figure 6(d), another circulation originates near the wing tip which is absent for $\mathrm{LR}=1$ to $\mathrm{LR}=3$. In figure 7, the mean drag coefficient is found to decrease with increase in $\mathrm{Re}$ for all the values of LR. Even for fixed Re, increase in LR causes decrease of mean drag which may be attributed to suppression of unsteadiness by extra length of flapper.

5.2b Effect of dihedral angle: For an aircraft or bird, dihedral angle is the upward angle of the wings. It increases the lateral stability which is actively controlled in both fixed wing aircraft and bird. Effect of dihedral angle $(\lambda)$ has been studied on variation of drag coefficient with Re. In the present study it has been varied from $-2^{\circ}$ to $6^{\circ}$. Figure 8 shows formation of flow structure at $\operatorname{Re}=400$ for two different values of dihedral angle. Swirling of flow has been observed for $\lambda=-2^{\circ}$ as seen in figure 8(a) which is absent in figure 8(b). In figure 9(a), decrease in drag coefficient 
takes place when $\lambda$ changes from $-2^{\circ}$ to $0^{\circ}$ for given $\mathrm{Re}$, beyond which it increases again. Variation of total pressure has been shown in figure 9(b) at a distance of $0.1 \mathrm{~d}$ from trailing edge along spanwise direction for two different values of dihedral angle. For higher value of $\lambda$, negative pressure is maintained up to $\mathrm{z}=10.5 \mathrm{~d}$ in comparison to $\mathrm{z}=$ $10 \mathrm{~d}$ for $\lambda=4^{\circ}$, which may be the cause of increase in drag coefficient.

\subsection{Unsteady flow past single bionic wing}

Properties of avian wings depend on the forested area, objective or purpose (like predatory birds have broad and slotted wings to carry heavy loads) and evolution (like bird evolved from dinosaurs named 'Paraves' and bat evolved from mammals). Studies of owl wing may inspire aircraft based on stealth properties. Seagull drifts along the coastal area with the help of thermals. Thermals are referred as upward currents of air. Teals are aquatic birds whereas bat wings are more flexible.

5.3a Effects on Reynolds number in flow past an owl wing: Figure 10(a) to (h) present time-averaged streamlines at mid-span of owl wing for different values of Re from 100 to
15000. It is observed that nature of circulation bubble formed at lower surface of the wing depends on the wing profile as well as flow Reynolds number. Flow gets detached from the surface due to adverse pressure gradient when fluid does not possess enough energy to continue its motion. At low velocity $(\mathrm{Re}=100)$, the circulation bubble is found to be absent and at $\mathrm{Re}=500$ a primary bubble appears at lower surface due to curvature effect of wing profile. Further increase in Re leads to formation of secondary bubble near the tail of the wing as shown in figure $10(\mathrm{c})$.

Figure 11 presents the flow structure for owl wing at $\operatorname{Re}=5000$ and 15000. It can be seen that at $\operatorname{Re}=5000$, there appears circulation zone on upper and lower surfaces of owl wing as in figure 11(a). A vortex tube can be seen at $\operatorname{Re}=5000$, at the lower surface of wing which gets busted at $\operatorname{Re}=15000$ due to the increase in dynamic pressure. This is supported by the presence of primary and secondary bubble formation in 2-D streamlines at mid-span of owl wing shown before in figure 10(f). Figure 11(b) corresponds to $\mathrm{Re}=15000$ where presence of circulation is observed only lower surface which is supported by the formation of single bubble in figure $10(\mathrm{~h})$.
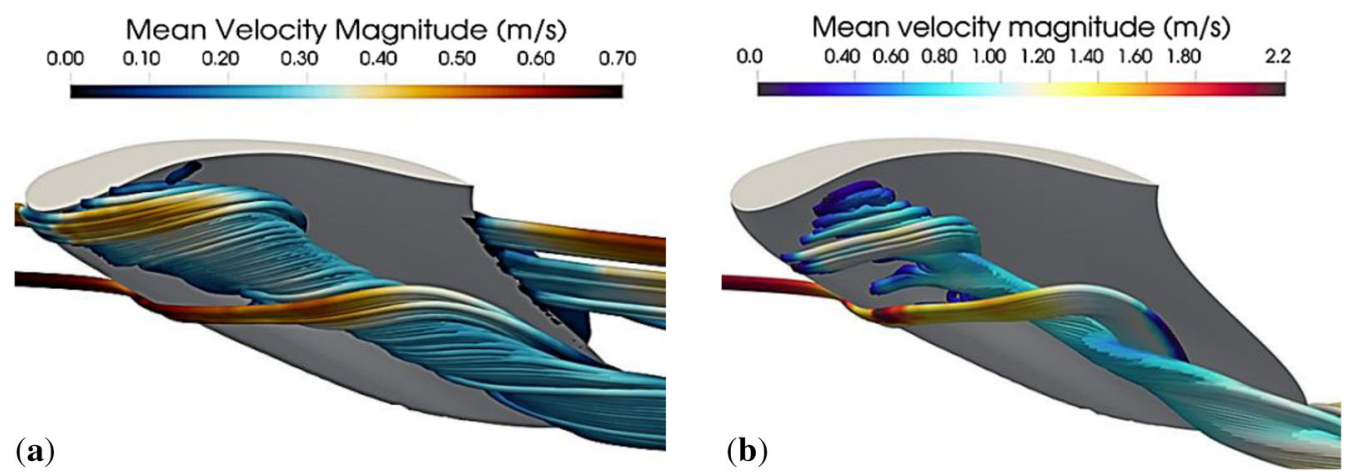

Figure 11. Flow structure for owl wing at (a) $\operatorname{Re}=5000$ and (b) $\operatorname{Re}=15000$.
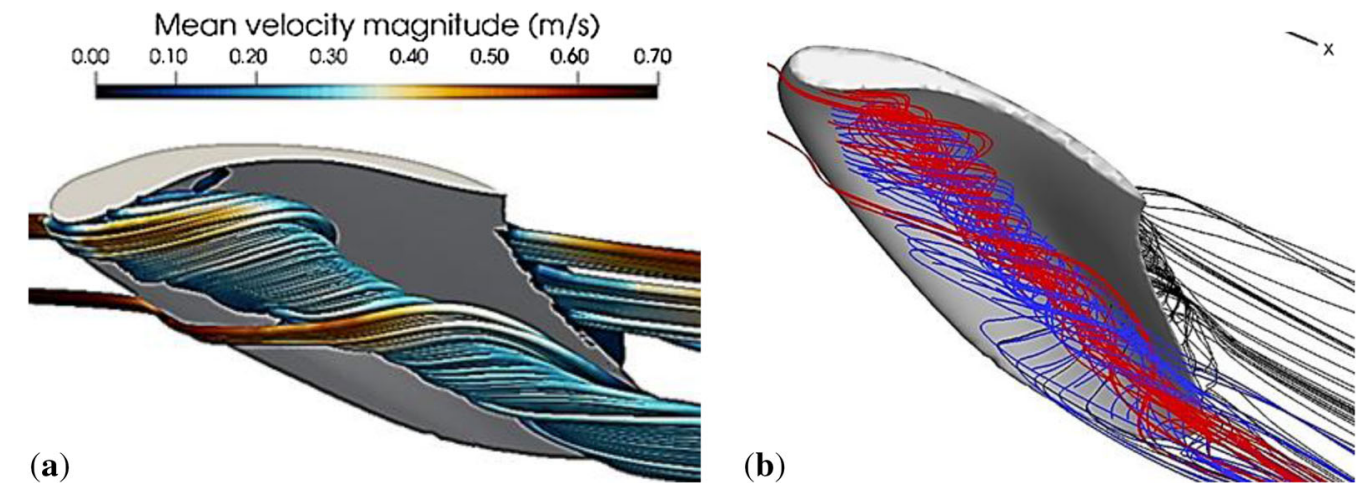

Figure 12. Flow visualization (a) with and (b) without mean velocity magnitude. 
(a)

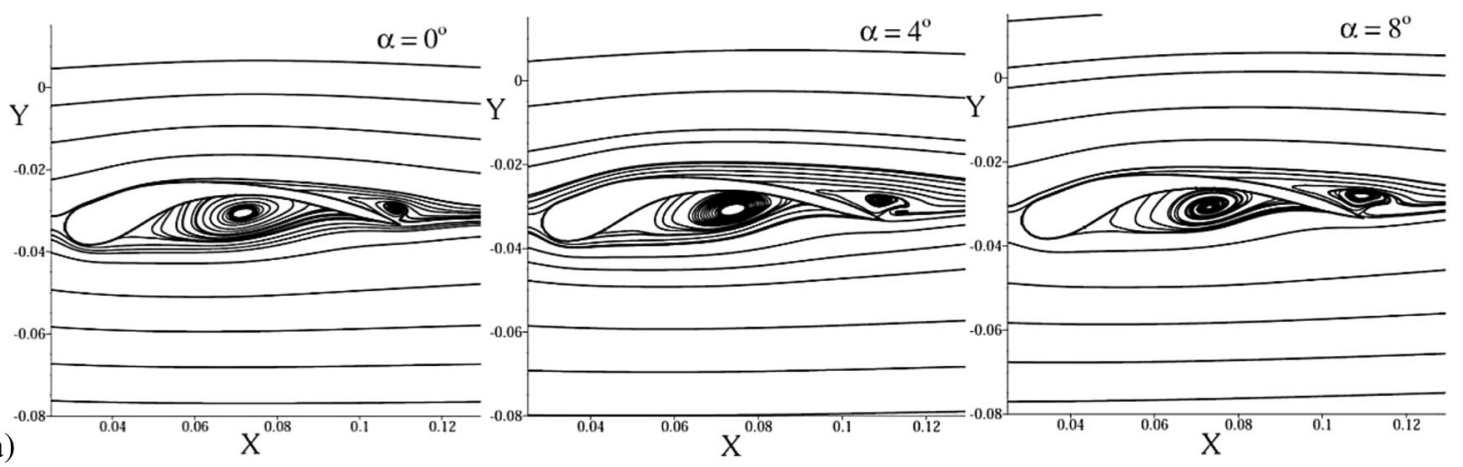

(b)

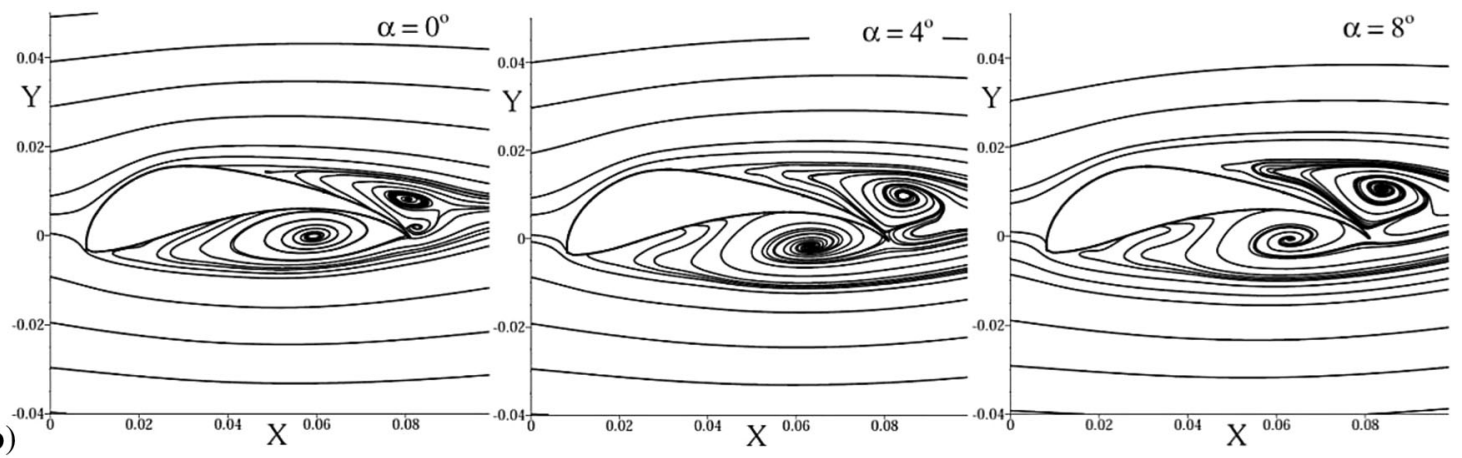

(c)

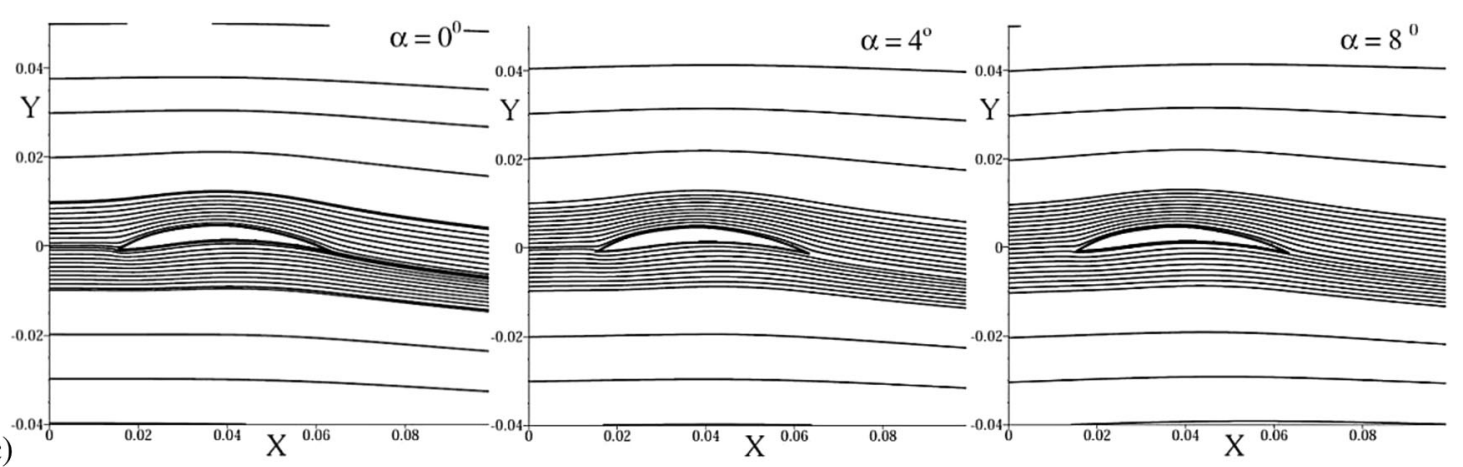

(d)
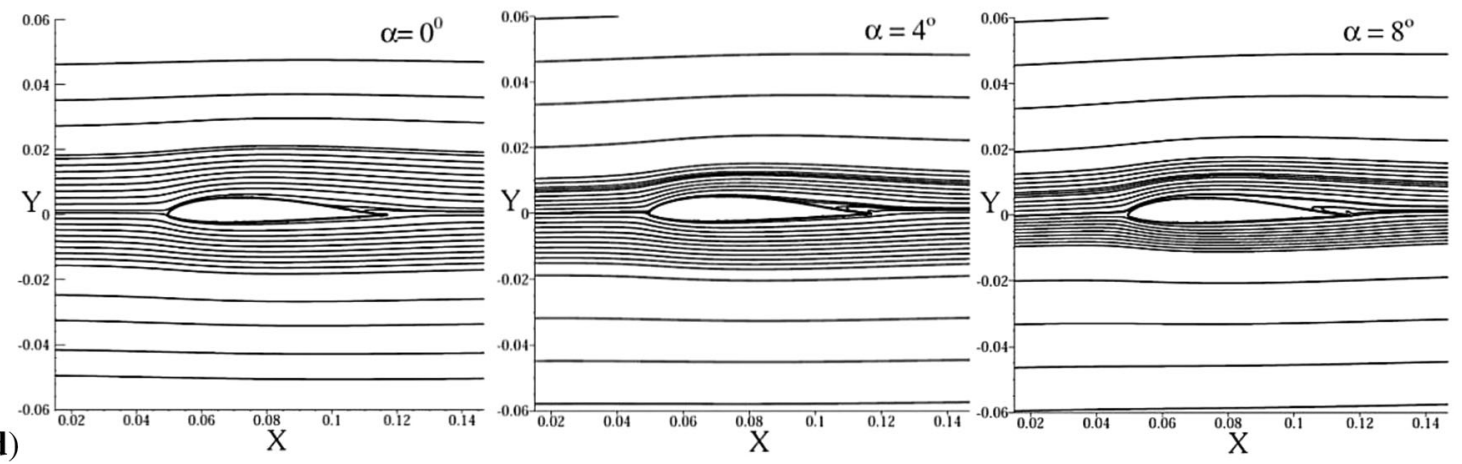

Figure 13. Streamline at mid-span for different values of angle of attack ( $\alpha$ ) for (a) owl wing, (b) seagull wing, (c) teal wing and (d) bat at $\operatorname{Re}=10000$.

To understand the fluid structure, a comparison has been shown in which stream surfaces with and without mean velocity magnitude legend are presented (figure 12).

5.3b Effect of angle of attack in flow past different wing shapes: Simulations have been carried out for $\mathrm{Re}=10000$ for different values of angle of attack. These cases mimic the situation of bird flight during take-off. Effect of angle of attack has been studied for different types of bird wings. Figure 13 shows the time-averaged streamlines at mid-span of different wings at $\mathrm{Re}=10000$ for varying angles of attack from $0^{\circ}$ to $8^{\circ}$. It is observed that for teal wing no 
(a)

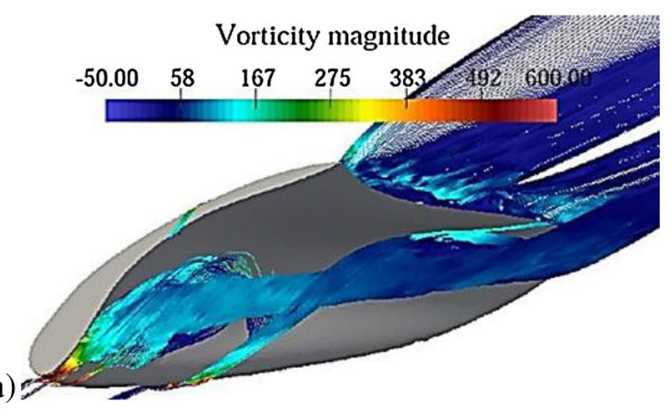

(c)

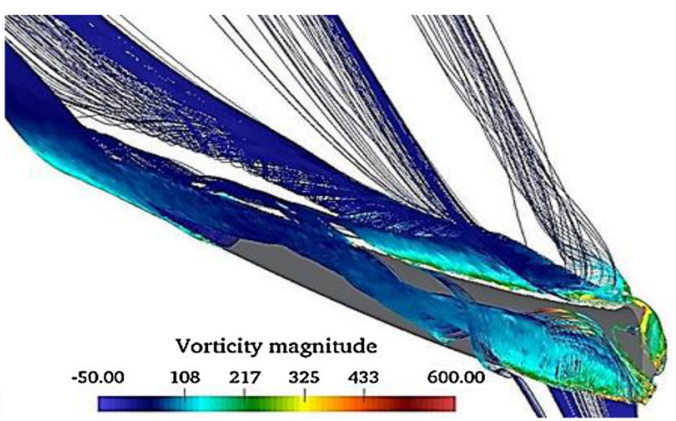

(e)

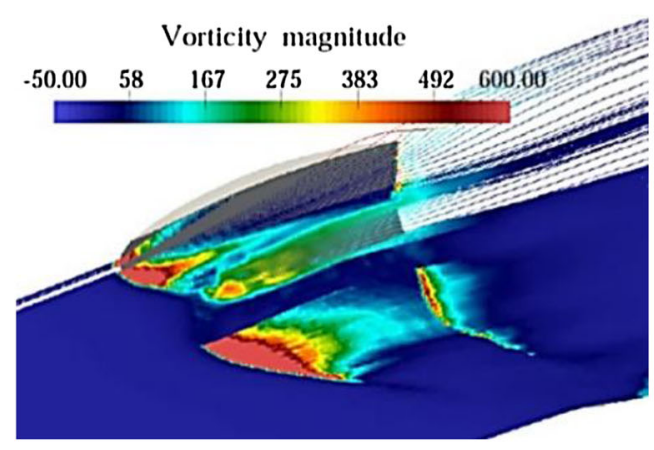

Vorticity magnitude

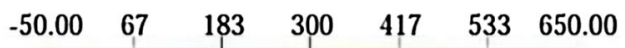

(g)

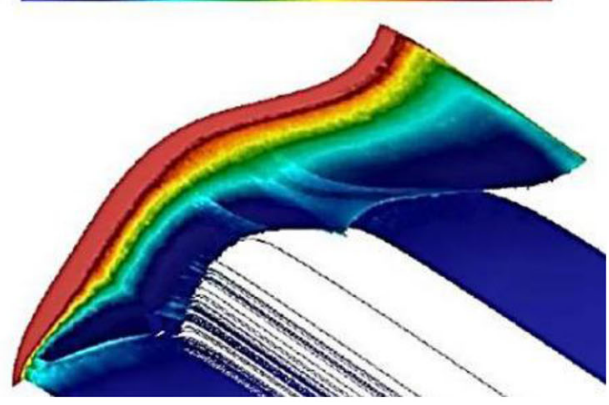

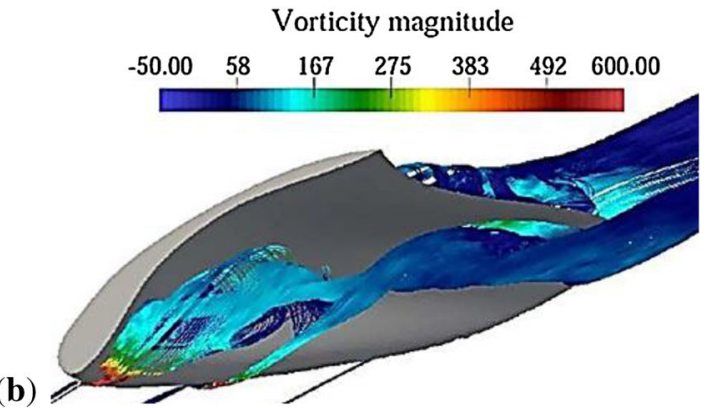

(d)

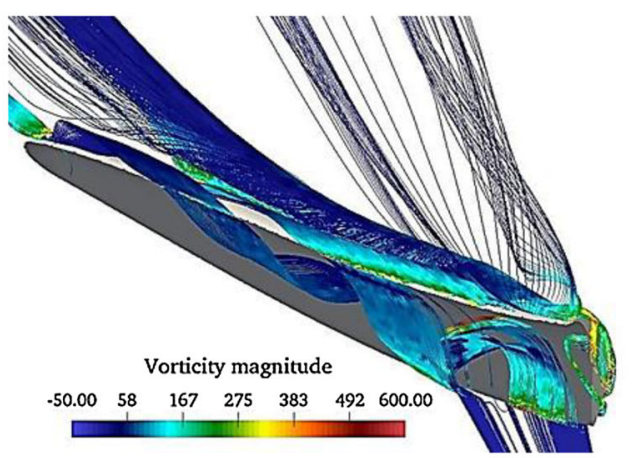

(f)

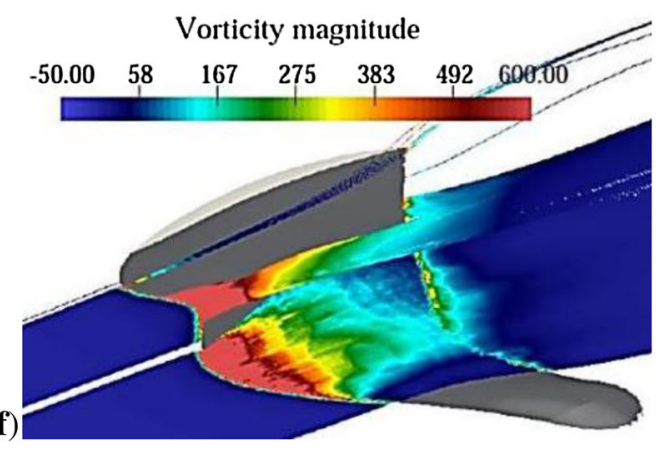

(h)

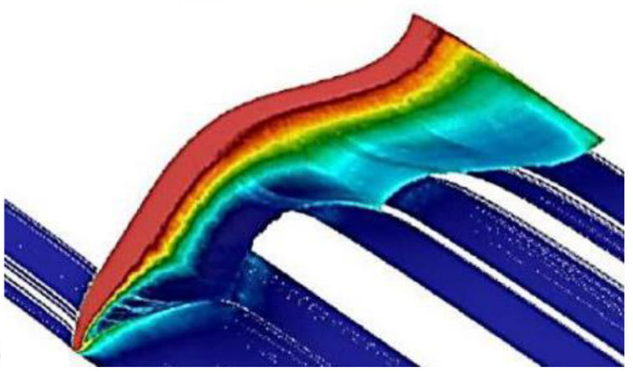

Figure 14. Vorticity magnitude at a position where lower and higher drag occurs for (a) owl at lower $C_{d}$, (b) owl at higher $C_{d}$, (c) seagull at lower $\mathrm{C}_{\mathrm{d}},(\mathbf{d})$ seagull at higher $\mathrm{C}_{\mathrm{d}}$, (e) teal at lower $\mathrm{C}_{\mathrm{d}}$, (f) teal at higher $\mathrm{C}_{\mathrm{d}}$, (g) bat at lower $\mathrm{C}_{\mathrm{d}}$ and (h) bat at higher $\mathrm{C}_{\mathrm{d}}$.

circulation occurs at $\operatorname{Re}=10000$ even at $\alpha=8^{\circ}$. Drag coefficient for teal wing is found to be lower as compared to other birds due to absence of circulation zone on upper and lower surfaces of the wing. For seagull wing, effect of angle of attack is more visible as compared to wings of other birds. For seagull at $\operatorname{Re}=10000$ and $\alpha=0^{\circ}$, primary 


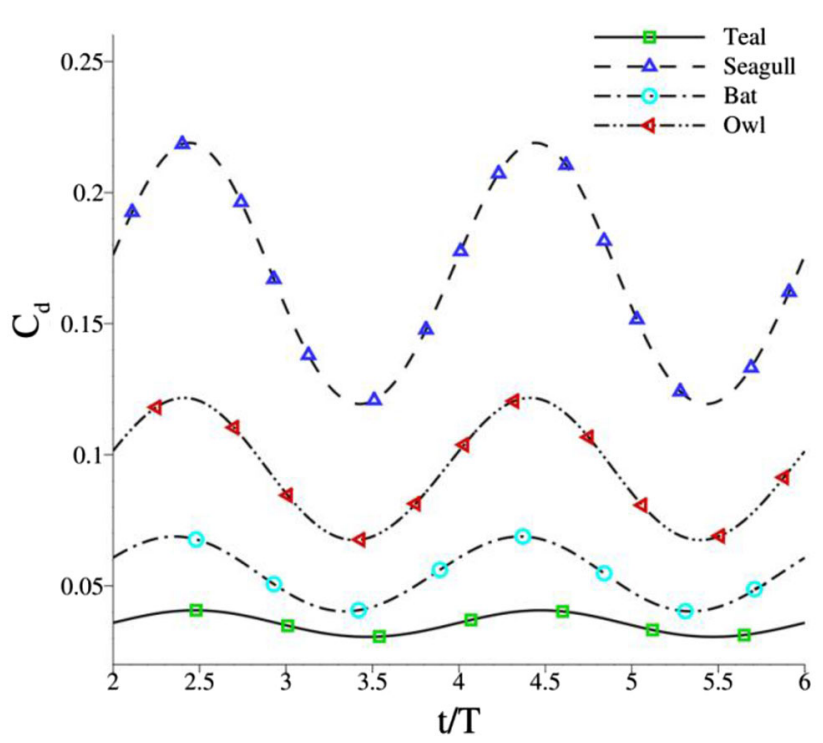

Figure 15. Variation of drag coefficient for different birds wing at $\operatorname{Re}=5000$ and $\mathrm{f}=1 \mathrm{~Hz}$.

bubble $\left(0.55 \mathrm{c}_{\mathrm{m}}\right)$, secondary bubble $\left(0.74 \mathrm{c}_{\mathrm{m}}\right)$, tertiary bubble $\left(0.77 c_{m}\right)$ and saddle $\left(0.81 c_{m}\right)$ have been observed where the information in the bracket gives position of bubble and
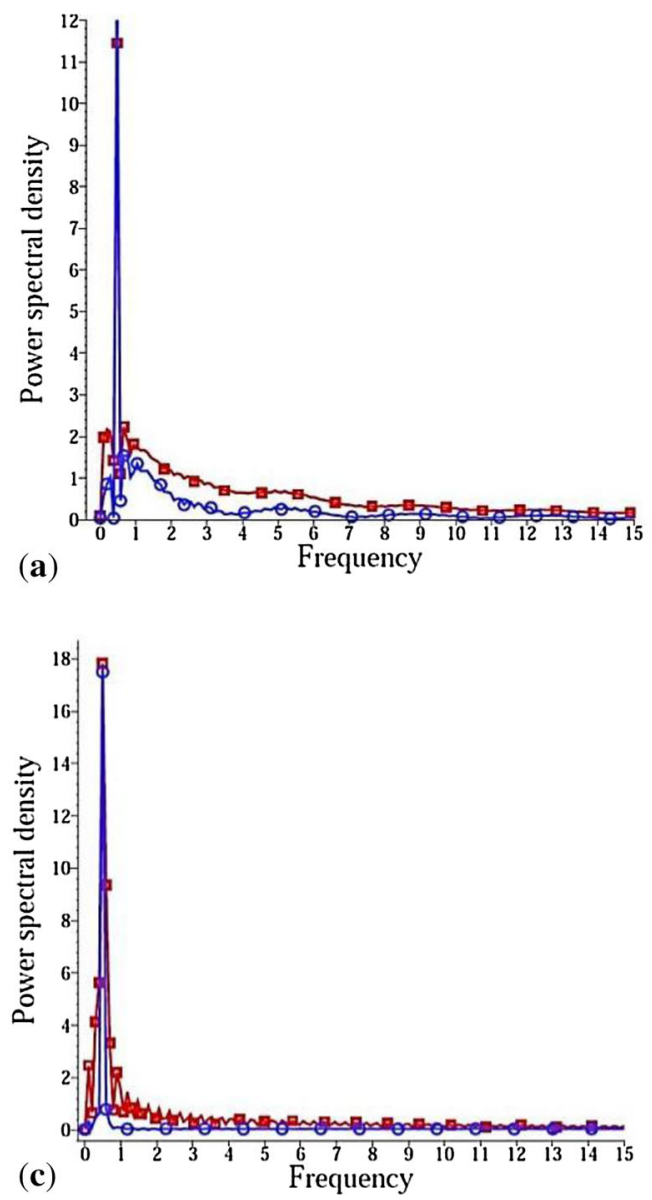

saddle from the leading edge. With increase in angle of attack, saddle and tertiary bubble get merged as seen in figure 13 (b) $\alpha=4^{\circ}$ to $8^{\circ}$. Only primary bubble and secondary bubble remain visible. For bat also there is no much visible effect and is similar to teal, except that the separation of flow can be seen at the tail of bat for different values of angle of attack as in figure 13(d).

5.3c Effect of pulsatile impinging flow over bionic wing: Aim of the present study is to numerically investigate the effect of gusty wind which can be replicated by perturbing the mean velocity. The flow conditions at inlet have been disturbed by imposing unsteady sinusoidal perturbation and the aerodynamic response has been computed in the form of lift and drag signals for different wing shapes. Mean velocity of flow is kept fixed corresponding to $\mathrm{Re}=5000$ and sinusoidal disturbance is imposed to inlet velocity giving rise to

$$
U_{\text {inlet }}=U_{\infty}+U_{A} \sin \left(2 \pi f_{\text {forced }} t\right)
$$

Figure 14 illustrates stream trace distribution superimposed with vorticity magnitude for different types of bird wings, i.e., owl, seagull, teal and bat corresponding to low and high value of drag when a pulsation flow of $1 \mathrm{~Hz}$ is
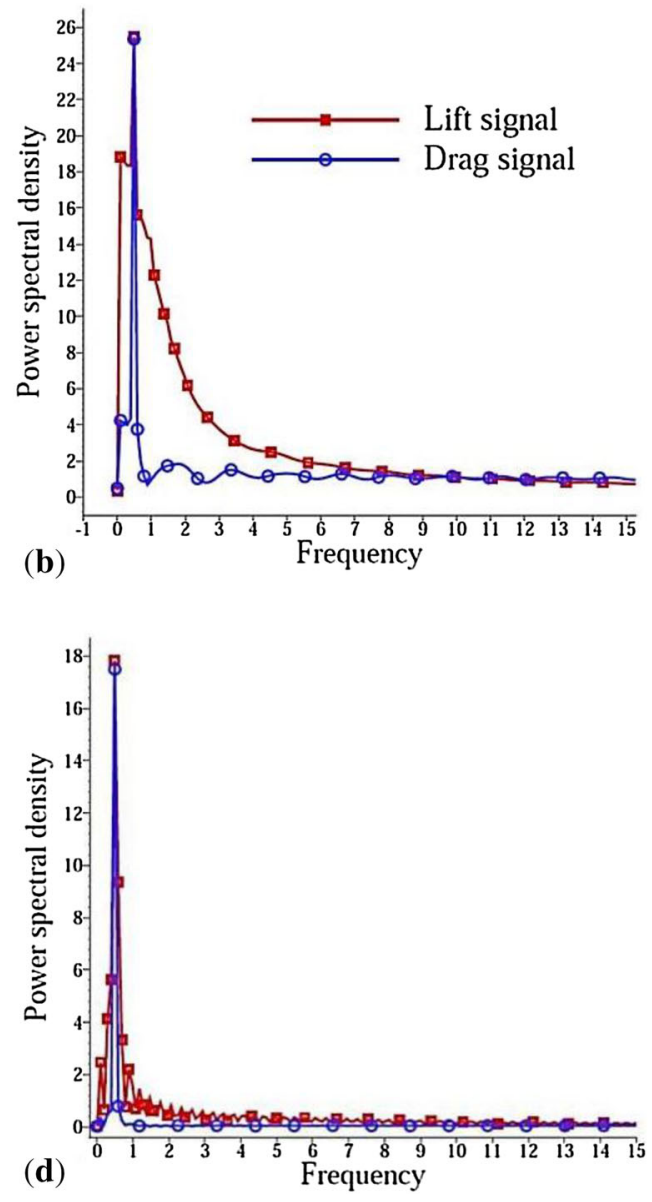

Figure 16. Frequency spectra obtained from lift signal for (a) owl wing, (b) seagull wing, (c) teal wing and (d) bat wing. 

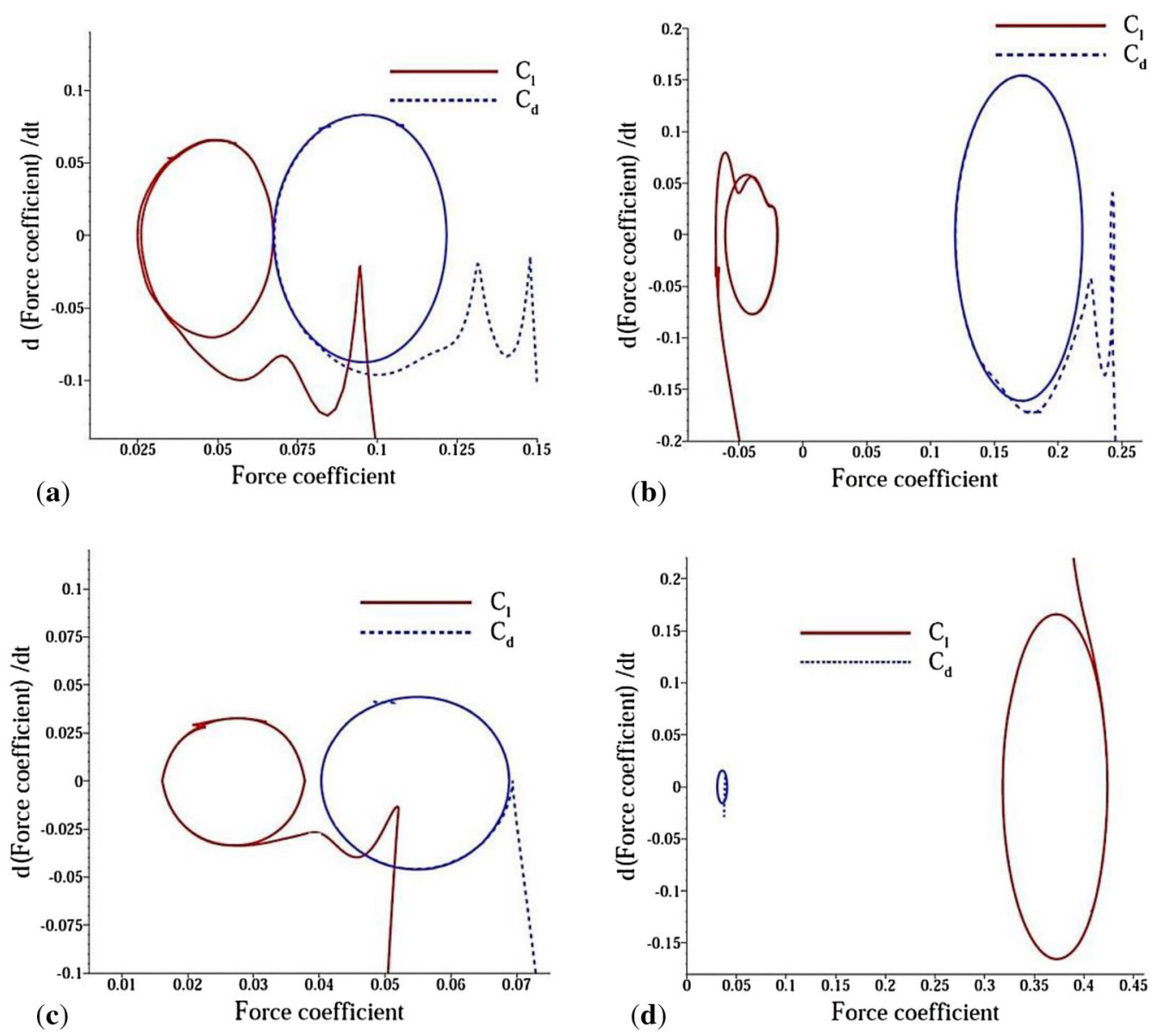

Figure 17. Phase portrait diagram for (a) owl, (b) seagull, (c) bat and (d) teal wing.

imposed on inlet velocity with amplitude of $0.1 \mathrm{~m} / \mathrm{s}$. From figure 14(a) and (b), it is observed that when drag corresponds to minimum value, the flow remains attached to upper surface of owl wing and gets detached when drag becomes higher. Variation of vorticity magnitude for seagull wing has been shown in figure 14(c) and (d). At an instant when drag is lowest, flow from the wing root gets attached to tip for both upper and lower surfaces of seagull wing whereas for higher drag flow generated by lower surface gets attached to wing tip but that from upper surface gets detached. For teal wing, higher vorticity region is found to be associated with higher drag in figure 14(f) as compared to that with lower drag in figure 14(e). In case of bat wing as well, the wing root is surrounded by flow of high vorticity for higher drag as in figure 14(h) as compared to lower vorticity region for lower drag in figure 14(e).

Figure 15 presents the time series of drag signal at $\mathrm{Re}=$ 5000 and pulsating frequency of $1 \mathrm{~Hz}$. It can be observed that drag amplitude is higher for seagull as compared to that for other wing shapes. In fact, owl and bat have relatively lower drag than seagull in descending order with teal having the lowest amplitude. Here the pulsating incoming flow mimics the situation of a gusty atmosphere. The results confirm that teal wing can offer better control towards drag reduction in gusty atmosphere. It is the special shape of teal wing that helps it adapt during its motion through both air and water.

Frequency spectra of lift signals have been presented in figure 16 for all the bionic wing models corresponding to pulsating flow frequency of $1 \mathrm{~Hz}$. It can be seen that for seagull wing highest peak occurs at $0.45 \mathrm{~Hz}$ and secondary peaks occur at $0.09 \mathrm{~Hz}$. Moreover, for owl, teal and bat wings, highest peak occurs at $0.5 \mathrm{~Hz}$. Results confirm that except seagull wing all wings have single dominant frequency that indicates the presence of less noise as compared to seagull wing. Thus, the interesting observation is that when a pulsating flow is imposed at inlet, all the wings show a common behaviour in terms of dominant frequency obtained from spectra of lift signal which is close to half of the flow frequency. For seagull wing, the spectra of drag signal shows only one dominant frequency at $0.48 \mathrm{~Hz}$ as compared to two of them in the spectra of lift signal as shown in figure 16(b). For all the wings, ratio of forced to 
the dominant frequency obtained from the lift signals is approximately equal to 2 . Thus, non-dimensional frequency ratio can be defined as $\bar{f}=\frac{f_{\text {forced }}}{f_{\text {lift }}}$.

Figure 17 is the phase portrait diagram obtained from the force coefficient for pulsating flow of $1 \mathrm{~Hz}$ frequency. Figure 17(a) shows the phase portrait diagram for owl wing, where both lift and drag signals have periodic nature and intersect each other. In figure 17(b) for seagull wing, lift coefficient shows non-periodic behaviour and drag shows periodic behaviour. For bat wing, both lift and drag show periodic nature as shown in figure 17(c). For teal, area under curve obtained from lift coefficient is much greater than that obtained from drag coefficient as in figure 16(d) which forms the main reason for its better performance under pulsating flow conditions.

\section{Conclusion}

Computations of flow past square prism with built-in flap confirm that increase in wing dimension in spanwise direction suppresses drag coefficient by stabilizing the wake. However, reduction in drag is not much significant beyond certain value of LR. Increment or decrement of dihedral angle affects the aerodynamic performance of the body such that associated drag forces first decrease up to $0^{\circ}$ and then increase. Simulations for owl wing show that even at higher Re (15000), stable circulation zone may exist while secondary circulation zone disappears beyond $\mathrm{Re}=$ 10000. As the angle of attack increases, the saddle zone near trailing edge of seagull disappears at the cost of increase in drag. Spectra of lift signal show that bird wings are designed such that the dominant frequency becomes half the pulsating frequency of impinging flow. Owl wing can demonstrates boundary layer separation at its lower surface. For seagull wing, the vortex core (imaginary centre around which fluid rotates) forms near both lower and upper surfaces and helps seagull to drift in air. Bubble formation at lower surface helps to stay aloft and by change in angle of attack seagull controls its forward and backward movements. For bat and teal, load response of $C_{d}$ suggests that magnitude of fluctuations is relatively less as compared to other wings.

\section{References}

[1] Bachmann T 2010 Anatomical, morphometrical and biomechanical studies of barn owls' and pigeons' wings (Master's thesis). Aachen: RWTH Aachen University

[2] Jacob J 1998 On the fluid dynamics of adaptive airfoils. Am. Soc. Mech. Eng. Aerosp. Div. 57: 167-176

[3] Shyy W, Lian Y, Tang J, Liu H, Trizila P, Stanford B, Bernal L, Cesnik C, Friedmann P and Ifju P 2008 Computational aerodynamics of low Reynolds number plunging, pitching and flexible wings for MAV applications. Acta Mech. Sin. 24(4): 351-373

[4] Bechert D, Bruse M, Hage W and Meyer R 2008 Fluid mechanics of biological surfaces and their technological application. Naturwissenschaften 87(4):157-171

[5] Brücker C and Weidner C 2014 Influence of self-adaptive hairy flaps on the stall delay of an airfoil in ramp-up motion. J. Fluid Struct. 47: 31-40

[6] Ennos A, Hickson J and Roberts A 1995 Functional morphology of the vanes of the flight feathers of the Pigeon Columba livia. J. Exp. Biol. 198(5): 1219-1228

[7] Brown R E and Fedde M R 1993 Airflow sensors in the avian wing. J. Exp. Biol. 179(1): 13-30

[8] Guerrero J E, Maestro D and Bottaro A 2012 Biomimetic spiroid winglets for lift and drag control. C. R. Mec. 340(1-2): 67-80

[9] Mazellier N, Feuvrier A and Kourta A 2012 Biomimetic bluff body drag reduction by self-adaptive porous flaps. $C$. R. Mec. 340(1-2): 81-94

[10] Withers P C 1981 An aerodynamic analysis of bird wings as fixed aerofoils. J. Exp. Biol. 90(1): 143-162

[11] Tulapurkar E G 2005 Hundred years of the boundary layersome aspects. Sadhna 30(4): 499-512

[12] Carruthers A, Walker S, Thomas A and Taylor G 2010 Aerodynamics of aerofoil sections measured on a free-flying bird. Proc. IME G J. Aerosp. Eng. 224(8): 855-864

[13] Chen K, Liu Q, Liao G, Yang Y, Ren L, Yang H and Chen X 2012 The sound suppression characteristics of wing feather of owl (Bubo bubo). J. Bionic Eng. 9(2): 192-199

[14] Geyer T, Sarradj E and Fritzsche C 2014 Measuring owl flight noise. In: Proceedings of the Inter-Noise Congress and Conference, Melbourne, Australia

[15] Tobalske B W, Hearn J W D and Warrick D R 2009 Aerodynamics of intermittent bounds in flying birds. Exp. Fluids 46(5): 963-973

[16] Moelyadi M A and Sachs G 2007 CFD based determination of dynamic stability derivatives in yaw for a bird. J. Bionic Eng. 4: 201-208

[17] Bostandzhiyan S, Bokov A and Shteinberg A 2008 Flexural characteristics and aerodynamic aspects of the design of the bird feather shaft. Dokl. Phys. 53(9): 476-479

[18] Stowers Amanda K and Lentink David 2015 Folding in and out: passive morphing in flapping wings. Bioinspiation Biomim. 10: 025001

[19] Tobalske B W 2010 Hovering and intermittent flight in birds. Bioinspiation Biomim. 5: 045004

[20] Dhawan S 1991 Bird flight. Sadhna 16: 275-352

[21] Hedenstrom A, Johansson L C and Spedding G R 2009 Bird or bat: comparing airframe design and flight performance. Bioinspiation Biomim. 4: 015001

[22] Liu T, Kuykendoll K, Rhew R and Jones S 2006 Avian wing geometry and kinematics. AIAA J. 44: 954-963

[23] Cedomir Kostic 2015 Review of the Spalart-Allamars turbulence model and its modification to three-dimensional supersonic configurations. Sci. Tech. Rev. 65:043-049

[24] A Crivellini, V D'Alessandro, D Di Benedetto, S Montelpare and R Ricci 2014 Study of laminar separation bubble on low Reynolds number operating airfoils: RANS modelling by means of an high-accuracy solver and experimental verification. J. Phys. Conf. Ser. 501:012024 
[25] Taira K, Dickson W B, Colonius T and Dickinson M H 2007 Unsteadiness in flow over a flat plate at angle-of-attack at low Reynolds numbers. AIAA Aerosp. Sci. Meet. Exhib. 45: 710-726

[26] Kondo K 2014 Computational comparative study for design of low Reynolds number airfoil. In: 29th Congress of the
International Council of the Aeronautical Sciences, St. Petersburg, Russia

[27] Soni A, Naik H and Tiwari S 2015 Three dimensional flow characteristics for flow along a square prism having built in side flaps. In: 42nd National Conference on Fluid Mechanics and Fluid Power, Surathkal, India 